
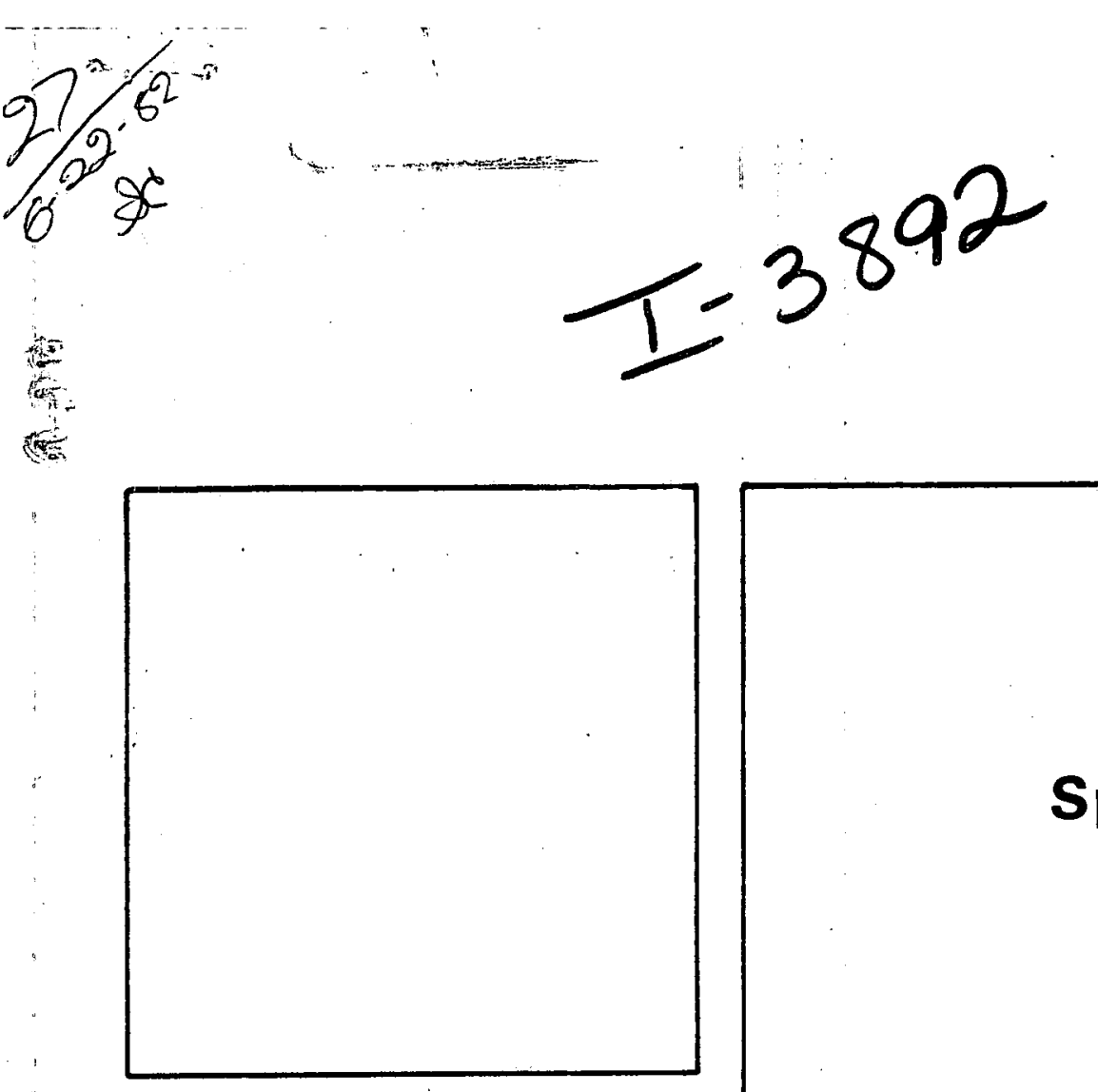

BDX-613-2709

\title{
Spin-Forming Development
}

\author{
By W. G. Gates
}

Published May 1982

Topical Report

Prepared for the United States Department of Energy Under Contract Number DE-ACO4-76-DPO0613.

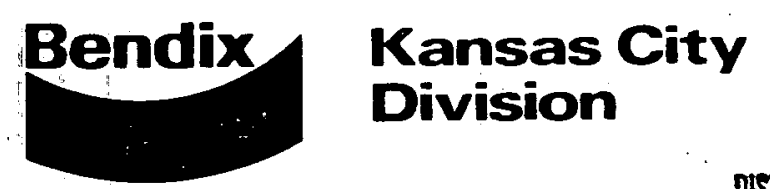




\section{DISCLAIMER}

This report was prepared as an account of work sponsored by an agency of the United States Government. Neither the United States Government nor any agency Thereof, nor any of their employees, makes any warranty, express or implied, or assumes any legal liability or responsibility for the accuracy, completeness, or usefulness of any information, apparatus, product, or process disclosed, or represents that its use would not infringe privately owned rights. Reference herein to any specific commercial product, process, or service by trade name, trademark, manufacturer, or otherwise does not necessarily constitute or imply its endorsement, recommendation, or favoring by the United States Government or any agency thereof. The views and opinions of authors expressed herein do not necessarily state or reflect those of the United States Government or any agency thereof. 


\section{DISCLAIMER}

Portions of this document may be illegible in electronic image products. Images are produced from the best available original document. 
This report was prepared as an account of work sponsored by the United States Government. Neither the United States nor the United States Department of Energy, nor any of their employees, nor any of their contractors, subcontractors, or their employees, makes any warranty, express or implied, or assumes any legal liability or responsibility for the accuracy, completeness or usefulness of any information, apparatus, product or process disciosed, or represents that its use would not infringe privately owned rights.

Printed in the United States of America

Available From the National Technical Information Service, U.S. Department of Commerce, 5285 Port Royal Road, Springfield, Virginia 22161.

Price: Microfiche $\$ 3.00$

Paper Copy $\$ 4.50$ 
$B D X--613-2709$

DE82 016993

Distribution Category UC-38

SPIN-FORMING DEVELOPMENT

By W. G. Gates

Published May 1982

Topical Report

W. G. Gates, Project Leader

Project Team:

M. G. Bryant

J. Hintz

D. B. Johnson

L. D. Webb

J. R. Wise

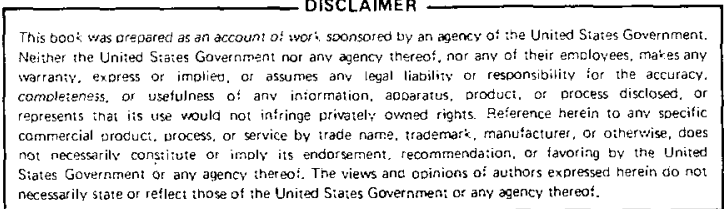

Technical Communications

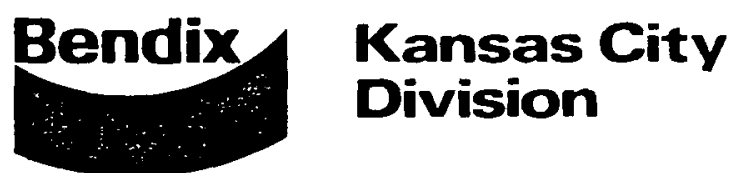

OSTRIBUTION OF THIS DOCUMENT IS UMLIMITEO 
.

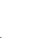


BDX-613-2709 Topical Report, Published May 1982

Prepared by W. G. Gates

Bendix product applications require the capability of fabricating heavy gage, high strength materials. Five commercial sources have been identified that have the capability of spin forming metal thicknesses greater than $9.5 \mathrm{~mm}$ and four equipment manufacturers produce machines with this capability. Twelve assemblies selected as candidates for spin forming applications require spin forming of titanium, 250 maraging steel, 17-4 $\mathrm{PH}$ stainless steel, Nitronic 40 steel, $304 \mathrm{~L}$ stainless steel, and 6061 aluminum. Twelve parts have been cold spin formed from a 250 maraging steel $8.1 \mathrm{~mm}$ wall thickness machine preform, and six have been hot spin formed directly from 31.8-mm-thick flat plate. Thirty-three $\mathrm{Ti}-6 \mathrm{Al}-4 \mathrm{~V}$ titanium alloy parts and 26 17-4 $\mathrm{PH}$.stainless steel parts have been hot spin formed directly from 31.8-mm-thick plate. Hot spin forming directly from plate has demonstrated the feasibility and favorable economics of this fabrication technique for Bendix applications.

FOA : TR26/a

This report was prepared as an account of work sponsored by the United States Government. Neither the United States, nor the United States Department of Energy, nor any of their employees. nor any of their contractors, subcontractors, or their employees. makes any warranty, expressed or implied or assumes any legal liability or responsibility for the accuracy. completeness or usefulness of any information. apparatus, product, or process disclosed, or represents that its use would not infringe privately owned rights.
The Bendix Corporation Kansas City Division P. O. Box 1159

Kansas City, Missouri 64141

\footnotetext{
A prime contractor with the United States Department of Energy under Contract Number DE-AC04-76-DPOO613
} 
$$
7
$$

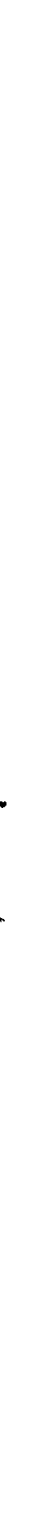

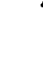

(1) 
CONTENTS

Section
SUMmary. . . . . . . . . . . . . . . . . . . . . . . . . 
$$
\text { 7 }
$$

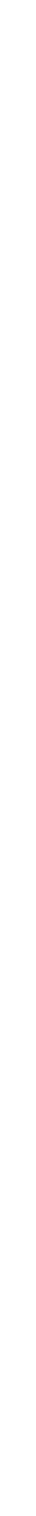

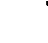

$=$

-

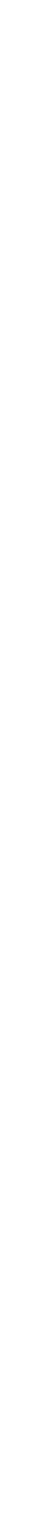




\section{ILLUSTRATIONS}

Figure

Page

$1 \quad$ Spin Forming Equipment Development stages

(R0775-01, P-112846) . . . . . . . . .

Spin Forming Techniques (R0775-02) . . . . . .

3 Development Time Schedule (Ro775-03) . . . .

17

4

250 Maraging Steel Spin Forming Preform $(\mathrm{R} 0775-04)$. . . . . . . . . . . . .

Major steps in Spin Forming 250 Maraging Steel Parts From Short Forgings or Flat Discs (R0775-05, P-111755, P-111756, $\mathrm{P}-111896$ ). . . . . . . . . . . . . . . . .

Cold Spin Formed 250 Maraging Steel Parts $(\mathrm{P}-112750, \mathrm{P}-111450)$. . . . . . . . . . .

Hot Spin Formed 250 Maraging Steel Parts Before Machining (P-112751). . . . . . . .

250 Maraging Part Formed on Single Roller Forming Machine, Showing Hole Required in End of Part $(\mathrm{P}-111896)$. . . . . . . . .

Major steps in spin Forming $6 \mathrm{Al}-4 \mathrm{~V}$ Titanium Part (R0775-06, P-111754, P-90610). . . .

6AI-4V Titanium Spin Forming Operations (R0775-07) . . . . . . . . . . . . . . .

Hot Spin Formed Titanium Part, as Formed and Sectioned (R0775-08, R0775-09).. .

Hot Spin Formed 17-4 PH Stainless steel Parts $(\mathrm{P}-111447)$. . . . . . . . . . . . . 
SUMMARY

Structural components must be lightweight, low in cost, reliable, and have high strength-to-weight ratios. Meeting these goals requires use of optimum manufacturing technology for each part configuration. Spin forming of metallic plate is a technique used to fabricate near net shape parts of rotational symmetry, such as hemispheres, cones, cylinders, and combinations of these configurations. The method is rapid, dimensionally accurate, produces little scrap, and results in properties that are generally equivalent or superior to those of castings, forgings, and extrusions. Tooling cost and lead times are generally low for spin formed parts, and the process is economical for short production runs.

For structures that can be made axially symmetric, spin forming is an attractive alternative to the current approach, which usually involves a machined forging. This development activity is providing basic information to Bendix and design agency engineers concerning the cost, performance, and characteristics of aluminum, titanium, and high strength steel structures manufactured by spin forming. The goals of this endeavor are to evaluate the feasibility, machinability and mechanical properties of spin formed titanium, steel, and aluminum alloy shapes and assemblies.

Initial investigations of the spin forming process indicated that the feasibility and resulting properties are very dependent on assembly geometry. In the past, the main deterrent to Bendix use of this spin forming process has been lack of both demonstrated feasibility and machining dimensional stability data for specific product applications. Furthermore, for the process to be attractive to Bendix, it must either be more economical than procured forgings or have other procurement or properties benefits. Therefore, to obtain pertinent data, present and future product applications were identified that were axially symmetric, geometrically suitable, and could potentially benefit from a spin forming capability. These applications require spin forming of 250 maraging steel, $6 \mathrm{Al}-4 \mathrm{~V}$ titanium, Nitronic 40 stainless steel, 17-4 PH stainless steel, and 6061 aluminum.

Spin forming vendors have been reviewed for the capability of fabricating Bendix assemblies. Bendix applications require that these vendors have the capability of fabricating heavy gage, high strength metals. Five commercial sources have been identified with the capability of spin forming metal thicknesses greater than $9.5 \mathrm{~mm}$ and four equipment manufacturers have been identified who build spin forming machines with this capacity. 
To date, 12 parts have been cold spin formed from $8.1-\mathrm{mm}$-wall thickness 250 maraging steel machine preforms, and six have been hot spin formed directly from 31.8-mm-thick flat discs. Thirtythree $6 \mathrm{Al}-4 \mathrm{~V}$ titanium alloy and 26 17-4 $\mathrm{PH}$ stainless steel parts have been hot spin formed directly from 31.8-mm-thick flat discs. Hot spin forming Bendix product applications from discs has demonstrated the feasibility and favorable economics of this process as an alternate fabrication technique to long-lead-time forgings. 


\section{SCUSSION}

\section{SCOPE AND PURPOSE}

The objectives of this project are to establish the feasibility, economics, and resulting properties of spin formed aluminum, steel, and titanium alloy near-net shapes that can be machined into Bendix Kansas City product configurations. Specifically, spin forming is being evaluated for geometrically suitable production parts that potentially can be produced using this process.

Spin forming produces a machining blank that requires less material removal and eliminates the need for long-lead-time procured forged or extruded preforms. If successful and economical, this process will be integrated into future Bendix product applications.

\section{PRIOR WORK}

No prior spin forming development has been done at Bendix. However, some development work has been done at the design laboratories; that technology and experience are being used to support this current activity.

\section{ACT IVITY}

Spin forming is being considered as an alternate to procured forgings for some applications. Bendix has never used this process in production because of a lack of capability and knowledge. Spin forming is very dependent on geometry, and some questions always arise about the feasibility of spin forming a specific shape.

- How will this shape machine?

- Will it have the dimensional stability necessary to produce an acceptable part?

- What are the final part's mechanical properties?

The use of spin formed assemblies is further complicated by the long procurement lead times required for forgings. Bendix is forced to buy production forgings early in development, long before spin forming can be developed for a specific application.

The spin forming process has a long history. The first recorded evidence of spin forming was documented in a middle ages' wood 
carving depicting the hand spinning of metal cookware, as shown in Figure 1. The early spinning process obviously was power limited, as the man shown in the background is supplying the power.

Spin forming took a large step forward with the advent of the electric motor and hydraulic power. As shown in Figure 1 , parts much larger in diameter, thicker in cross section, and from higher-strength materials could be fabricated. However, this process essentially was still a hand-controlled operation and very dependent on the operator's skill.

The recent technological breakthrough that is revolutionizing spin forming is computer numerical control (CNC). Machines similar to the one in Figure 1 can now be programmed to provide the versatility of a skilled spin forming operator and still produce the part-to-part consistency of a cam-controlled machine. Machines currently being produced have the power and control necessary to hot spin form titanium or high-strength steel product configurations directly from flat plate in one operation.

\section{Spin Forming Technology}

Technically, spin forming can be broken into the three classic types of operations (Figure 2): free spinning, flow turning, and shear forming; this terminology is used to define the specific type of metal deformation taking place during the spin forming operation. In each of these techniques, an initial preform or spinning blank is revolved at a controlled rate of speed on a specialized machine similar to a lathe. Instead of the clamping chuck column on a lathe, a wood, cotton phenolic, or metalspinning mandrel similar to those shown in Figure 2 are used. These mandrels correspond to the final contour of the part being produced.

Free spinning is used primarily on thin-gage sheet metal and the initial starting blank is a circular disc. The blank is clamped between the mandrel and the tail stock spindle. The mandrel, blank, and tail stock are then set into rotation. The spinning tools or rollers are forced against the rotating blank causing it to bend toward the mandrel. Several passes of the roller, from the blank center to the periphery, are required to work the blank to the shape of the mandrel. During free spinning, the part completely contacts the mandrel on the last spinning pass of the roller, and the part is complete. Little metal deformation or thickness change results during free spinning; therefore, the final mechanical properties and grain structure of the finished part are essentially the same as the initial material.

Flow turning is used exclusively on straight-walled open- or closed-end cylinders. The initial starting material is either a 

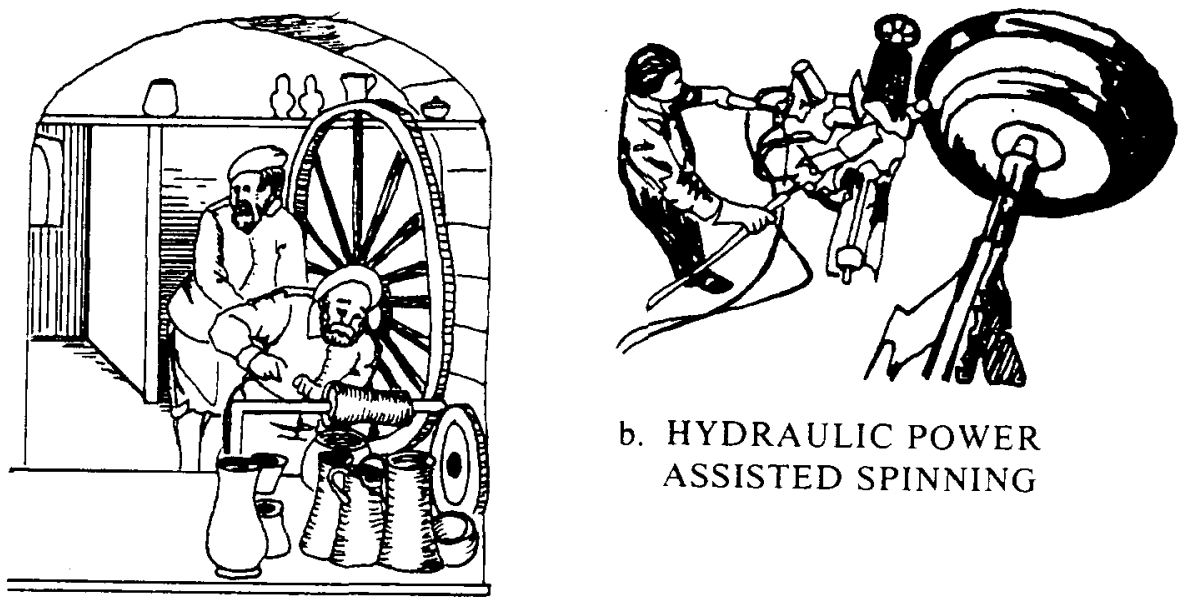

b. HYDRAULIC POWER
ASSISTED SPINNING

a. 16th CENTURY

HAND SPINNING

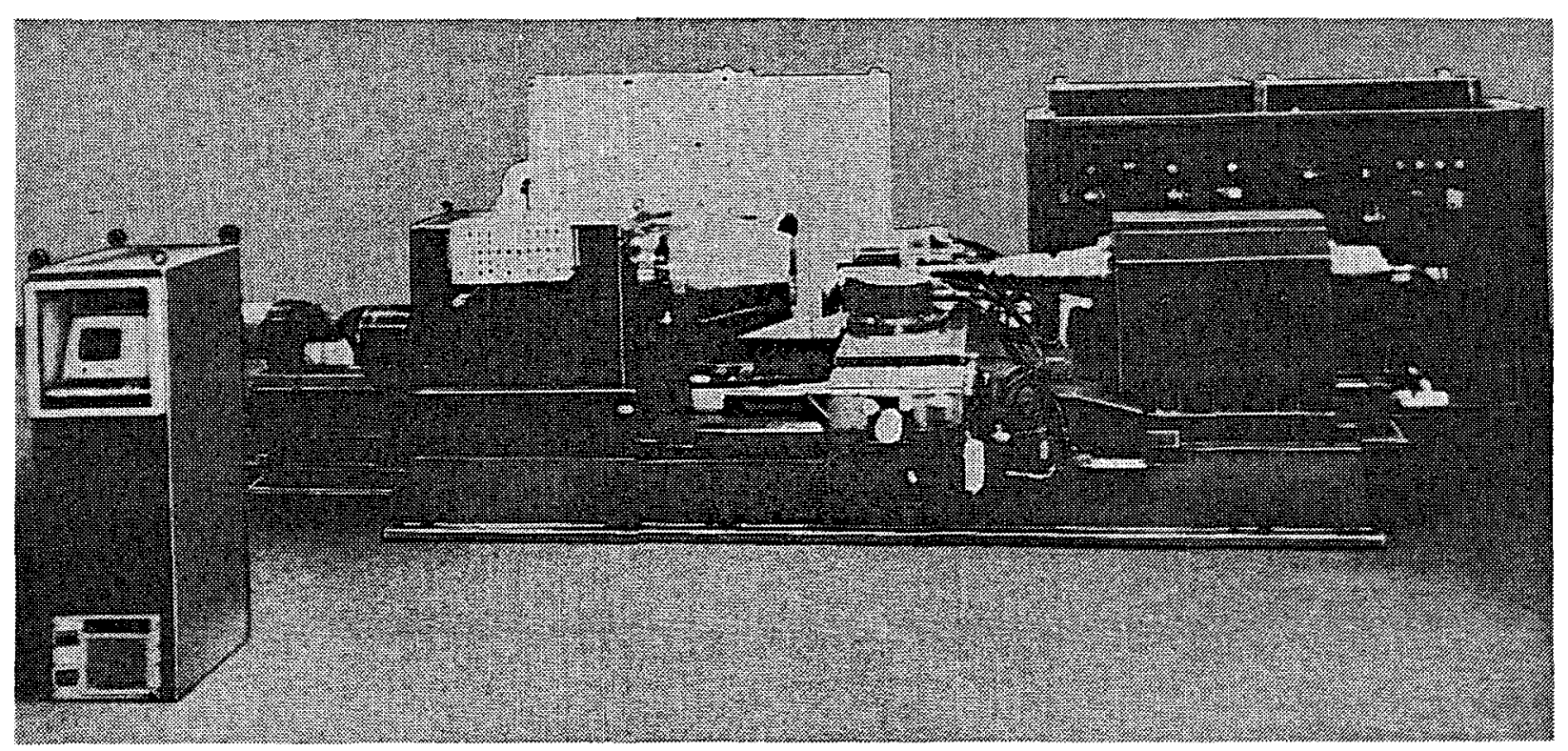

c. COMPUTER CONTROLLED POWER SPINNING

Figure 1. Spin Forming Equipment Development Stages

short forging or rolled and welded preform. The metal thickness is reduced as the cylinder is rotated and the roller pressure extrudes the material against the mandrel. The cylinder also becomes longer as the excess material "flows" down the mandrel. Flow turning can be done on the inside or the outside of material being formed. Because considerable metal deformation occurs as the metal thickness is reduced, the mechanical properties of the final material can be improved and the grain structure refined. 


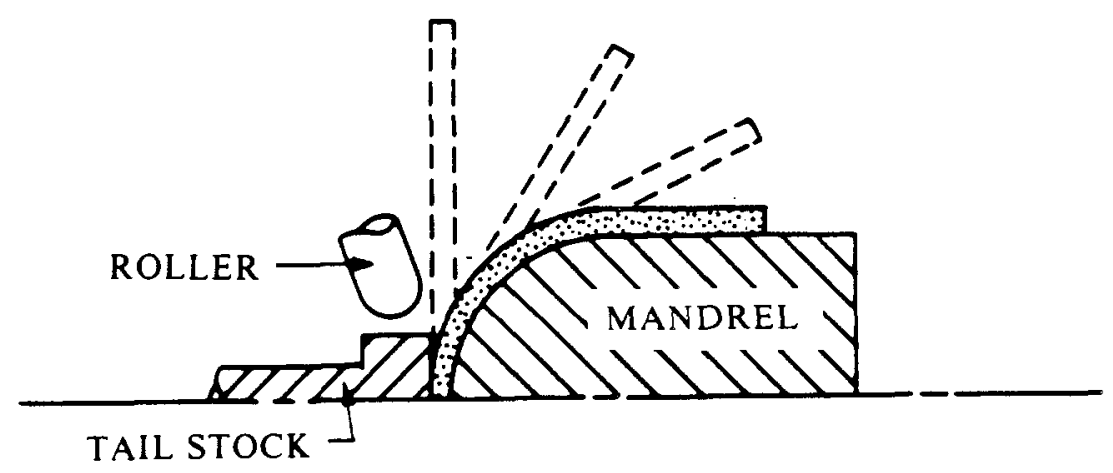

a. FREE SPINNING

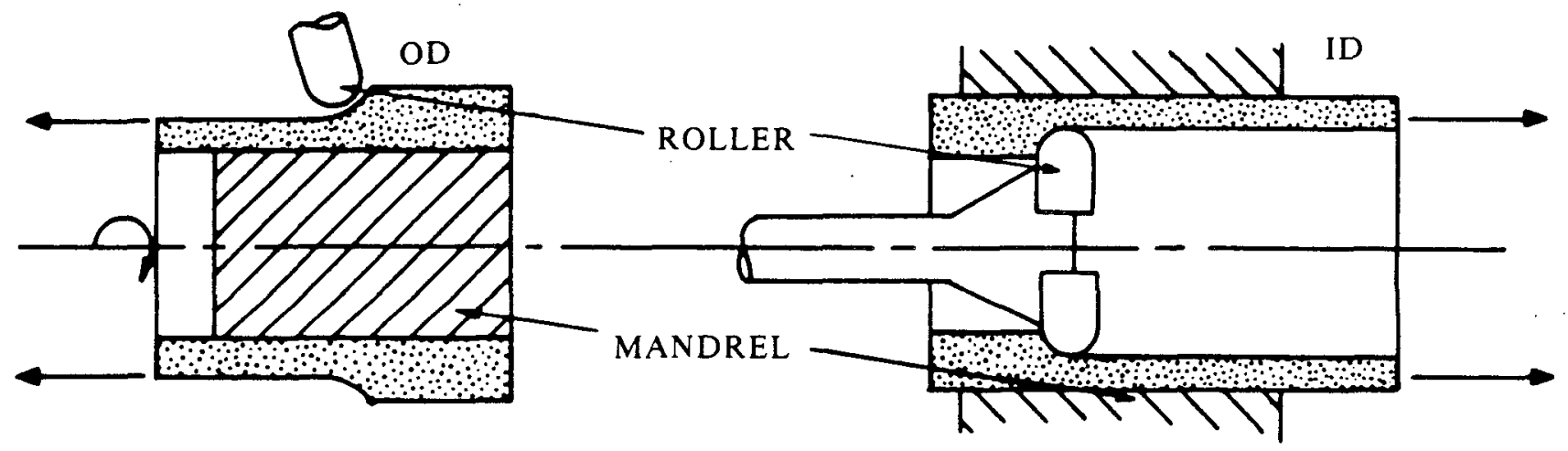

b. FLOW TURNING

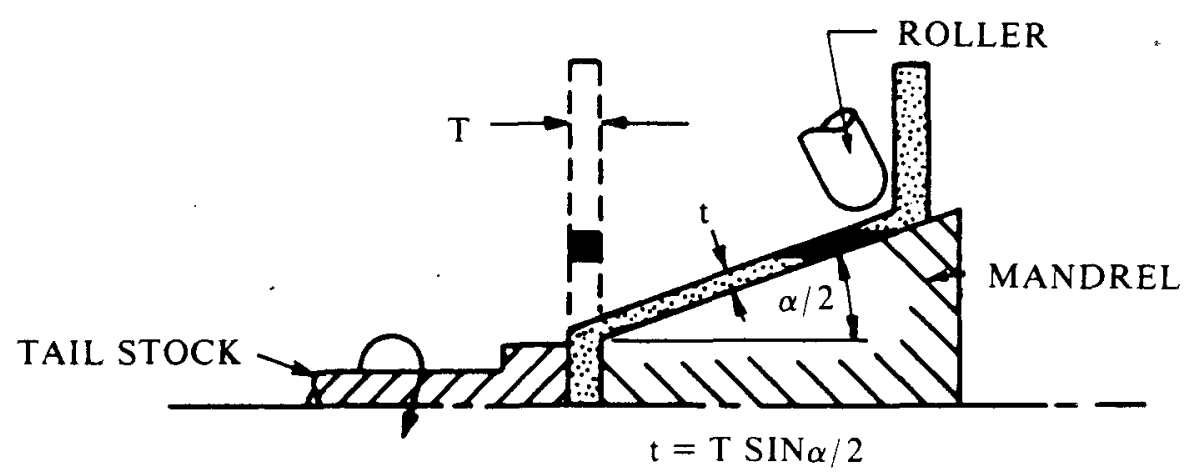

c. SHEAR FORMING

Figure 2. Spin Forming Techniques (All three techniques may be required to produce a single part.)

Shear forming is used to fabricate cones and hemispheres. Deformation occurs in one pass of the roller, and the process gets its name from the manner in which the metal deforms. As shown by the small element in Figure 2, the material deforms by the shear mechanism, and the final thickness is a function of the initial 
thickness and the spin forming mandrel half angle. The final thickness is defined by the sine law equation given in Figure 2 . During shear forming, the unformed portion of the blank and the actual deformation remain at right angles with respect to the axis of rotation, and the external dimensions of the unformed portion do not change. Thus, circular, square, or odd-shaped blanks may be shear formed into conical or hemispherical components. Because considerable metal deformation takes place during forming, the final mechanical properties of the material can be improved and the grain structure refined.

The spin forming of parts of complicated geometry similar to many Bendix applications may require incorporation of all these techniques. All three of these operations can be accomplished on a single piece of spin forming equipment.

For parts axially symmetric and geometrically suitable, spin forming has several distinct advantages. It provides an alternate to forgings that currently represent a long-lead procurement item for Bendix. It potentially can lower final part cost by reducing the forging and tooling cost. And, by producing parts nearer to net shape, it will minimize machining cost and material waste by eliminating the need to pay for the material once and then pay again to convert the extra metal into chips. Finally, spin forming can improve the final material properties by cold working or by thermal mechanical treatment.

\section{Development Tasks}

The development tasks established for this project were to define from the literature the state of the art in spin forming; to identify all spin forming vendors and equipment manufacturers; to identify candidate product applications; to establish the feasibility of spin forming from flat or rolled and welded preforms; and to establish the machinability, dimensional stability, properties, and costs of spin forming for applicable Bendix product. Currently, twelve parts have been identified as geometrically suitable and, potentially, will benefit from the development of this technology.

During past design agency program development activities, some parts were spin formed at Los Alamos National Laboratory (LANL). However, current production assemblies are being fabricated by Bendix from purchased forgings. The primary reason for using forgings has been the lack of available commercial sources to hot spin form these heavy-gage, complicated-geometry parts.

Seven parts were selected for initial development. These parts were chosen because they are geometrically suitable to the spin forming process and have a high potential for utilizing this process in production. Development time schedules for spin 
forming these selected parts are shown in Figure 3. In addition, spin forming equipment procurement and support activities are being planned.

Procurement of a CNC spin forming machine is planned to support the transfer of this technology to Bendix. This CNC machine's computer system must be interfaced into the Bendix computer system. Interface of this computer system to the future computeraided design and manufacturing (CAD-CAM) capability is desirable. The CAD-CAM system, coupled with additional computer programs defining the spin forming roller positions/metal deformation process, has the potential for considerable dollar savings both by reducing spin forming machine development time and by minimizing use of expensive materials in the development phase of new product applications.

\section{Vendor and Equipment Review}

A written survey was made of 40 vendors, inquiring about their spin forming capabilities. Seven of these vendors then were selected for further consideration. Product drawings were mailed, with a request for a formal quotation, and visits were made to each of the companies.

Spin forming of Bendix products directly from plate, thus eliminating forgings, requires a powerful machine with hot spin forming capabilities. To date, only one commercial firm, has been identified that has equipment capable of hot spin forming titanium or maraging steel in section thicknesses large enough to support Bendix applications. Procurement of a hot spin forming machine will be required to support future development in production spin forming programs.

Four manufacturers of spin forming machines make equipment powerful enough to hot spin form Bendix applications. Only one has equipment currently available that is capable of doing development spin forming of Bendix assemblies.

Product Development

\section{Maraging Steel Parts}

Developmental parts were hot flow formed by LANL to support requirements. LANL's starting preforms were machined from solid bars of 250 maraging steel to the configurations shown in Figure 4. The parts were flow turned on a two-roller cincinnati 45-50 machine [55.2 kW (75 horsepower) main drive and $111.2 \mathrm{kN}$ (25,000 pound)roller force]. The parts were heated to $816^{\circ} \mathrm{C}$, and three passes of the rollers reduced the wall thickness to $5.1 \mathrm{~mm}$ and increased the length to $464.3 \mathrm{~mm}$. The Bendix investigation was initiated to establish a commercial spin 
PRODUCT EVALUATION

EQUIPMENT EVALUATION

CAD/CAM SUPPORT

PURCHASE EQUIPMENT

EQUIPMENT INTEGRATION
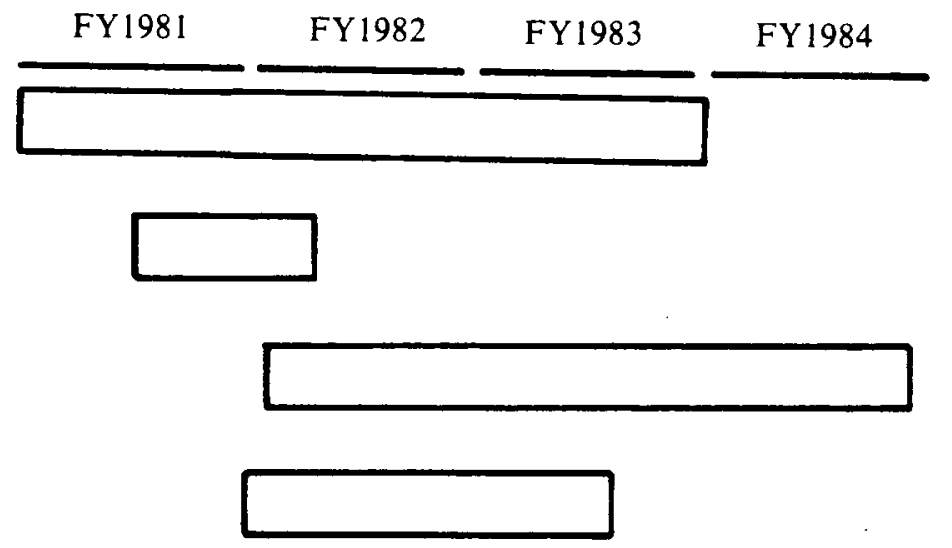

Figure 3. Development Time Schedule

forming source to produce machining preforms to support production requirements. Two techniques (Figure 5) were evaluated. The first technique was to cold flow turn machine preforms from an initial short forging blank, and the second approach was to hot shear form/flow turn the machining preform from a flat disc. Cold flow forming was done by one vendor, and the hot shear forming/flow turning was done by another. Both techniques successfully produced the configurations necessary for machining.

The first of these vendors was willing to do development spin forming and has considerable experience cold flow turning 250 maraging steel for other commercial applications. Although these previous applications were thinner in cross section, the vendor was willing to try the thicker sections required for this evaluation.

The vendor's spin forming machine has a $29.4-\mathrm{kW}$ (40-horsepower) main drive, $14.7-\mathrm{kW}$ (20-horsepower) hydraulic pumps, $93.4-\mathrm{kN}$ (21,000-pound) roller force, and $84.5-\mathrm{kN}$ (19,000-pound) feed force. The absolute maximum thickness that this machine will flow form in maraging steel for this part configuration is $12.7 \mathrm{~mm}$. The vendor was more comfortable with $8.1 \mathrm{~mm}$ on the first set of parts. A total of 12 parts were cold spin formed for evaluation. The initial preforms were machined from bar stock. Production preforms would be procured short forgings. A set of four cold flow turned parts and four machined cold flow turned parts are shown in Figure 6. The vendor left $0.79 \mathrm{~mm}$ machine stock all around for final machining. Two of the first four machined parts did not clean up during machining. The vendor made corrections on the second set of assemblies and these currently are being machined at Bendix. 


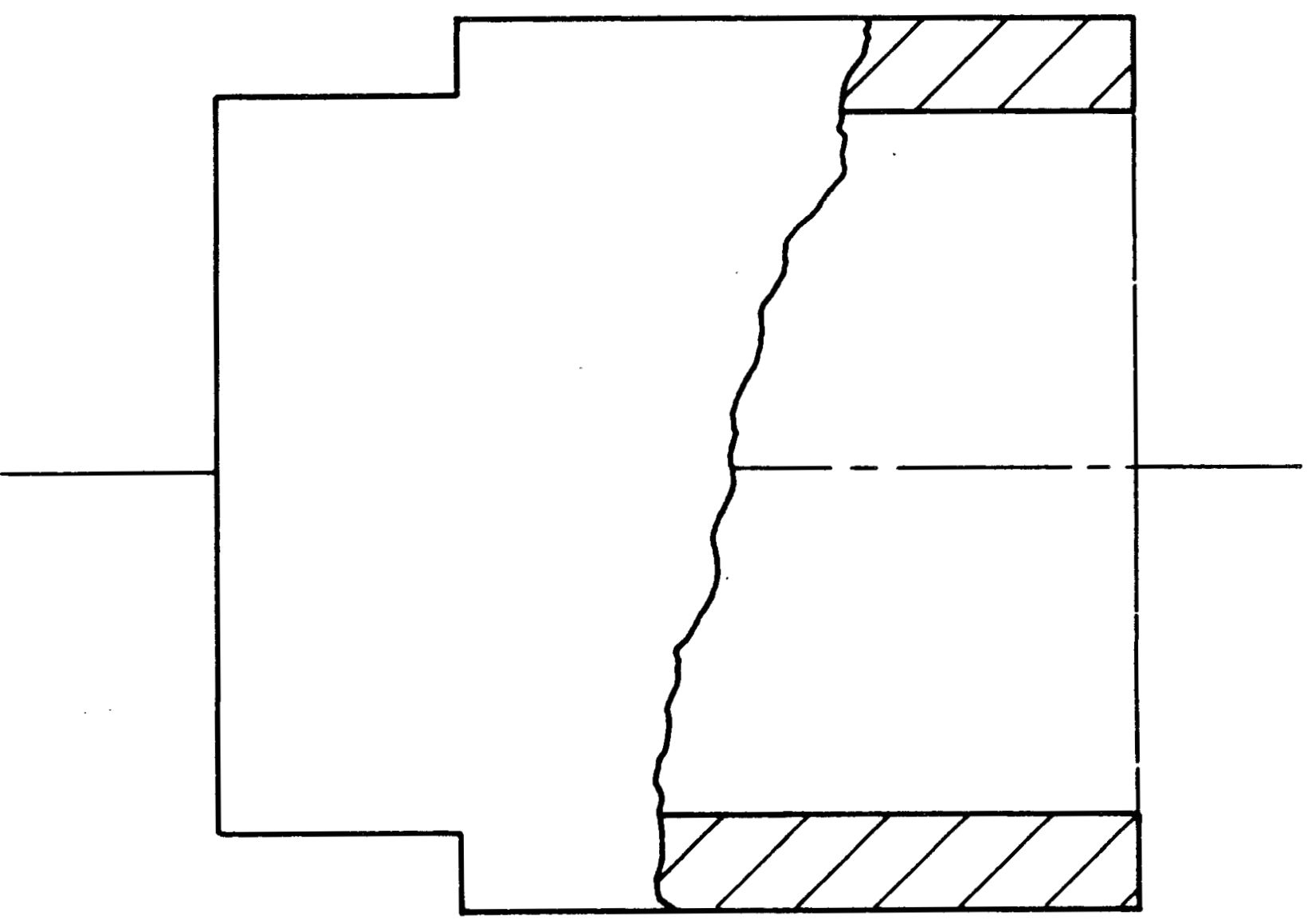

Figure 4. 250 Maraging Steel Spin Forming Preform

The first four cold flow turned assemblies were dimensionally inspected before and after annealing and before and after heat treating. A distortion of $0.203 \mathrm{~mm} / \mathrm{mm}$ was observed on the open end, and $0.025 \mathrm{~mm} / \mathrm{mm}$ on the closed end was observed after the 1 -hour, $843^{\circ} \mathrm{C}$ anneal. A uniform shrinkage of $0.0127 \mathrm{~mm} / \mathrm{mm}$ was observed after the 3 -hour, $482^{\circ} \mathrm{C}$ aging.

For this process to be economical, a forging preform with a $25.4 \mathrm{~mm}$ wall thickness would be desirable. A shorter, thickerwalled forging minimizes the material lost during machining of the forging preform to initial spin forming tolerances.

Only one vendor has the commercial capability of hot spin forming this 250 maraging steel application and they demonstrated the feasibility and their capability by forming parts directly from flat discs $31.8 \mathrm{~mm}$ thick by $356 \mathrm{~mm}$ diameter. Six parts were hot spin formed, using two spin forming operations, to a final wall thickness of $10.2 \mathrm{~mm}$. The first operation was to hot shear form 


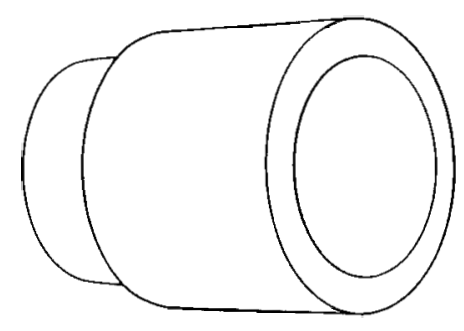

FORGING
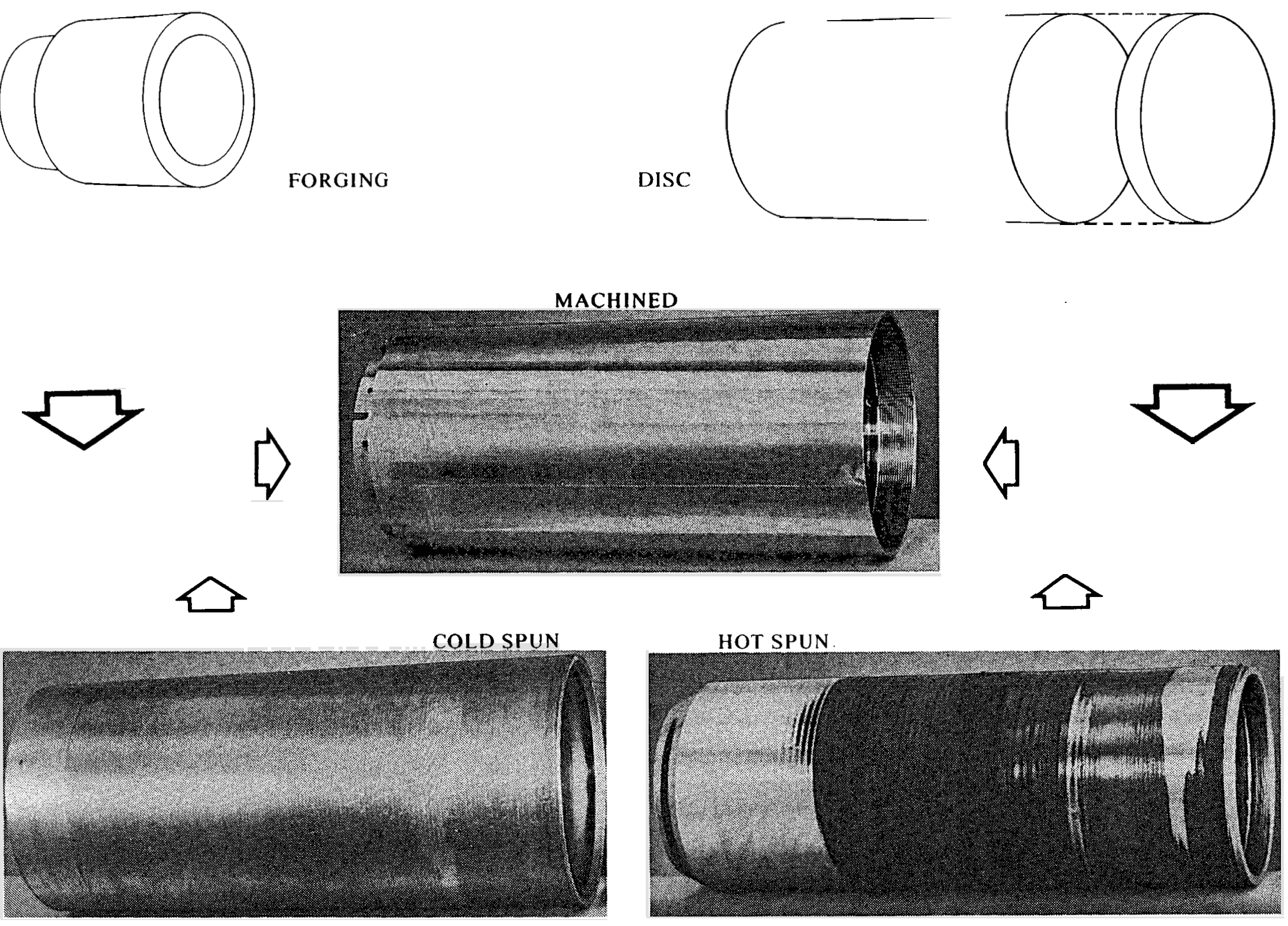

Figure 5. Major Steps in Spin Forming 250 Maraging Steel Parts From Short Forgings or Flat Dises 


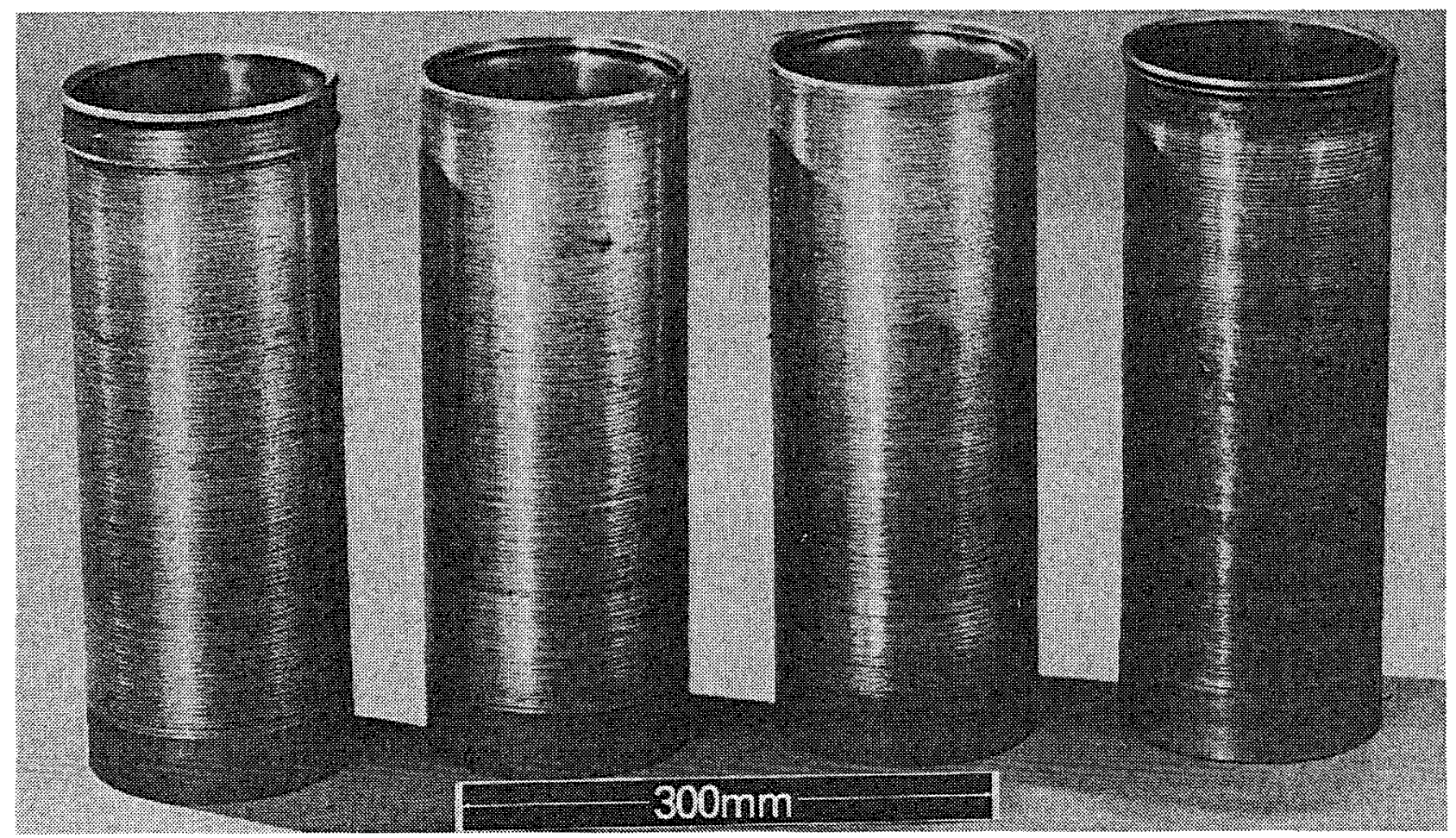

a. BEFORE MACHINING

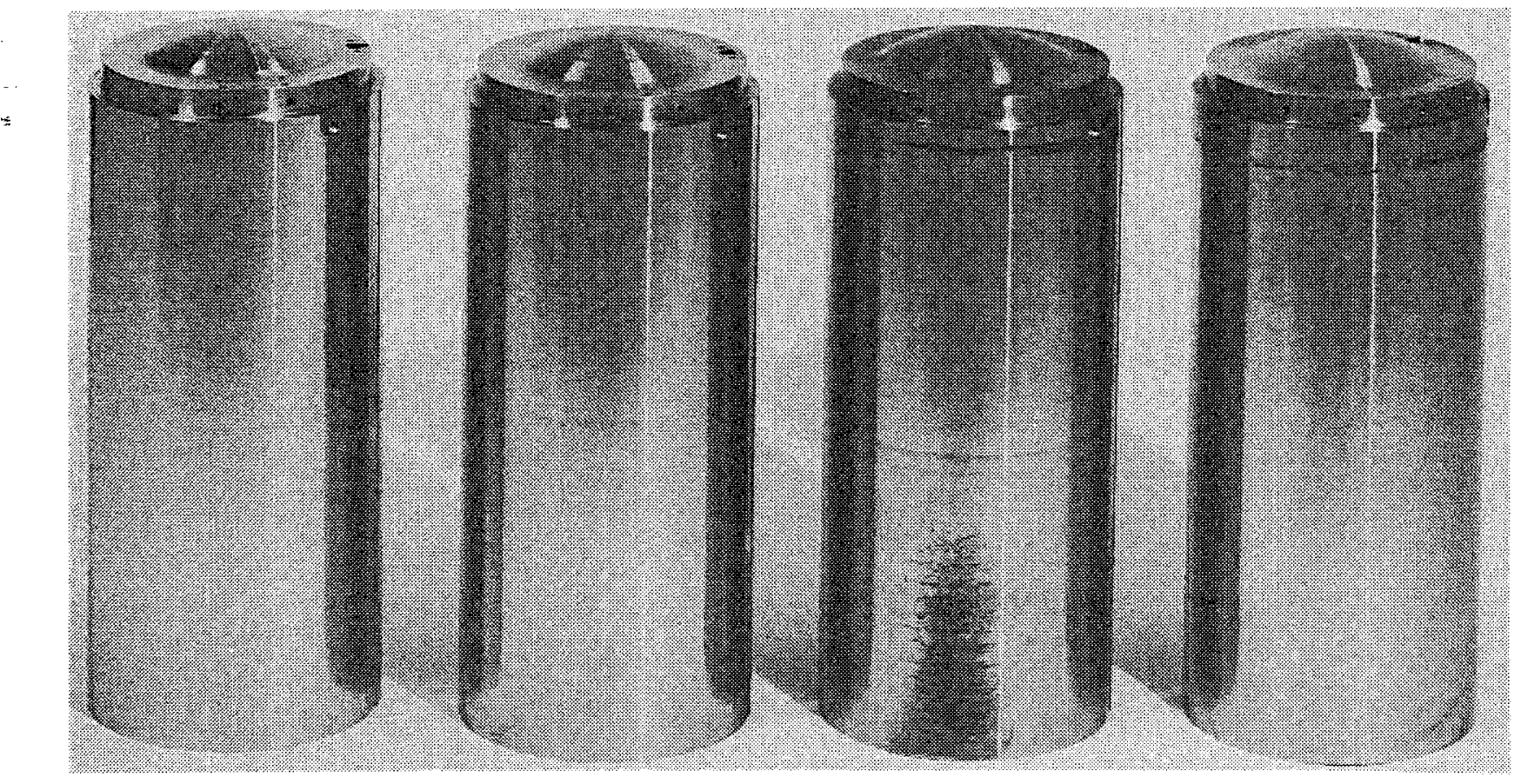

b. AFTER MACHINING

Figure 6. Cold Spin Formed 250 Maraging Steel Parts 
the flat discs into a frustum of a $56^{\circ}$ cone. The second was to spin this cone onto a straight mandrel. Currently, four of these parts (Figure 7) are being machined and evaluated for machineability and dimensional stability. Further spin forming development could reduce the initial blank size and reduce the final wall thickness to nearer the final size.

The second vendor's machine has a single-roller with a $33.1 \mathrm{~kW}$ ( 45 horsepower) head stock. This machine has been modified to increase the roller force and to allow hot spin forming. Because it is a single roller machine and the spin forming forces are not balanced, the hole in the end of the part, shown in Figure 8 , was required. A pin in the mandrel is necessary to carry the roller load and to keep the preform from sliding off the mandrel. On future parts, this hole could be changed to a 9.53-mm countersunk hole; the hole can be eliminated on a two-roller machine because the second roller balances the spin forming forces.

\section{$6 \mathrm{Al}-4 \mathrm{~V}$ Titanium Parts}

This second vendor has successfully hot spin formed parts from 31.8-mm-thick by 292-mm-diameter flat discs of 6Al-4V titanium (Figure 9). These parts now are being machined, evaluated, and compared to forgings for machineability, dimensional stability, and mechanical properties.

An equipment manufacturer has spin formed 26 parts on their machine (Figure 10). These assemblies (Figure 11) are also being evaluated and compared to forgings for machineability, dimensional stability, and mechanical properties.

\section{7-4 PH Stainless Steel Parts}

Because titanium sometimes is hard to procure and expensive, an alternate material is desirable. Use of 17-4 PH stainless steel is being considered for this application. However, 17-4 PH stainless steel may not have the dimensional stability to maintain the required machining tolerances. Twenty-six 17-4 PH stainless steel flat discs $31.8 \mathrm{~mm}$ thick and $292 \mathrm{~mm}$ diameter, have been hot spin formed as shown in Figure 12. These parts are being machined and compared for machineability, dimensional stability, and mechanical properties.

\section{Nitronic 40 Stainless steel Parts}

A machined cylinder of Nitronic 40 (21-6-9) stainless steel is required. Fabrication of a welded cylinder, and spin forming or roll extruding to length as shown in Figure 13 is being considered as a cost effective alternate to forgings. The cold work introduced into the part during spinning will result in recrystallization of the weld during annealing. Therefore, this process 


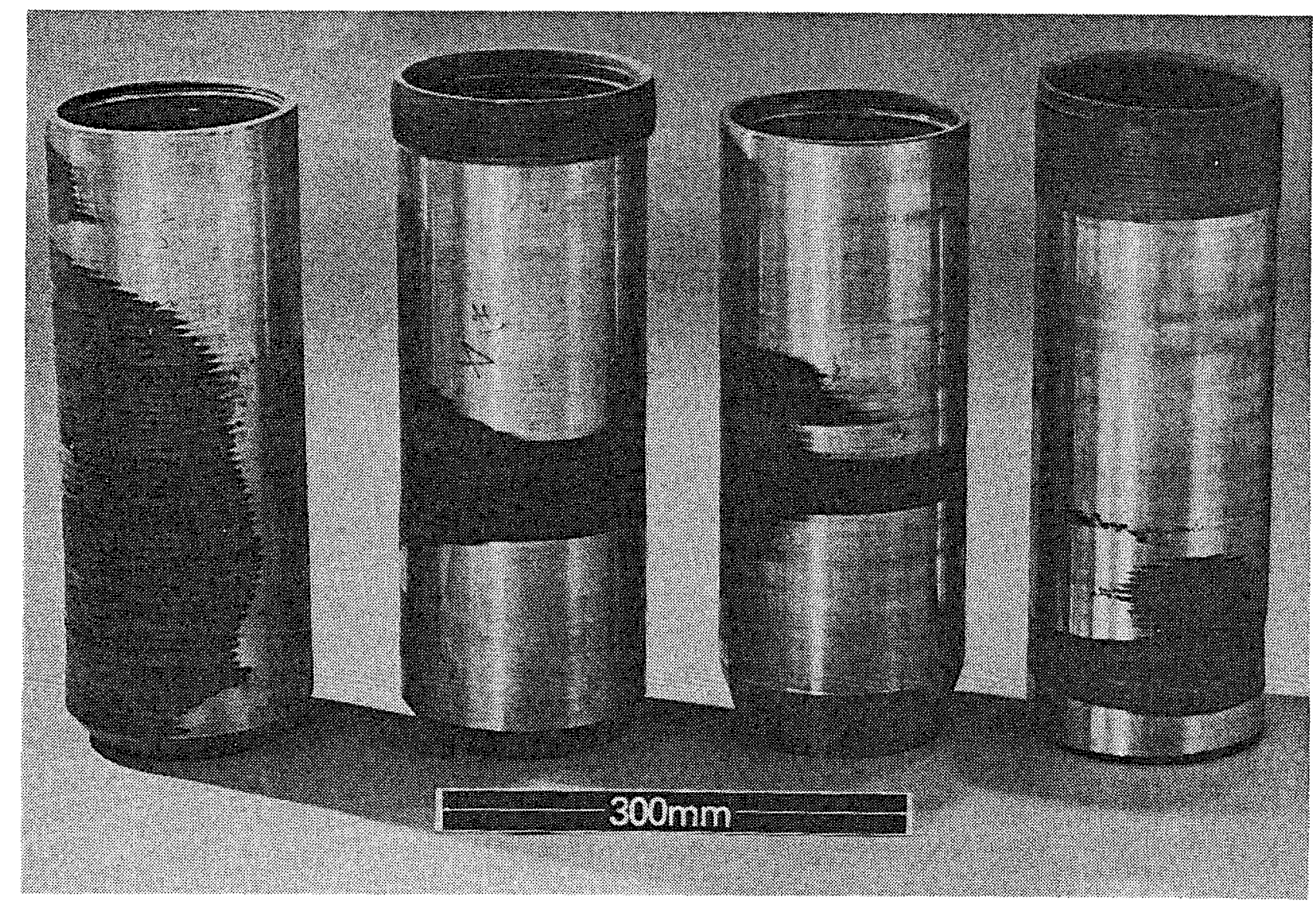

Figure 7. Hot Spin Formed 250 Maraging Steel Parts Before Machining

should produce a dimensionally stable machining preform with mechanical properties equal to a forging. Currently, purchase orders have been placed to press brake cylinders; submerged arc weld; and spin form the cylinders to length.

\section{Cost Analysis}

The actual cost of fabricating three current production titanium assemblies from forgings has been compared to the estimated cost of fabrication by spin forming. This cost comparison assumes that spin forming will be done on a Bendix-owned machine. For these three titanium parts, the total cost of the machined part is significantly less when the part is fabricated by spin forming. These costs were based on current forging and machining costs, estimated spin forming costs, and current wrought material costs.

Spin forming produces parts nearer to net shape than forging, eliminating some initial rough machining and, therefore, saving 


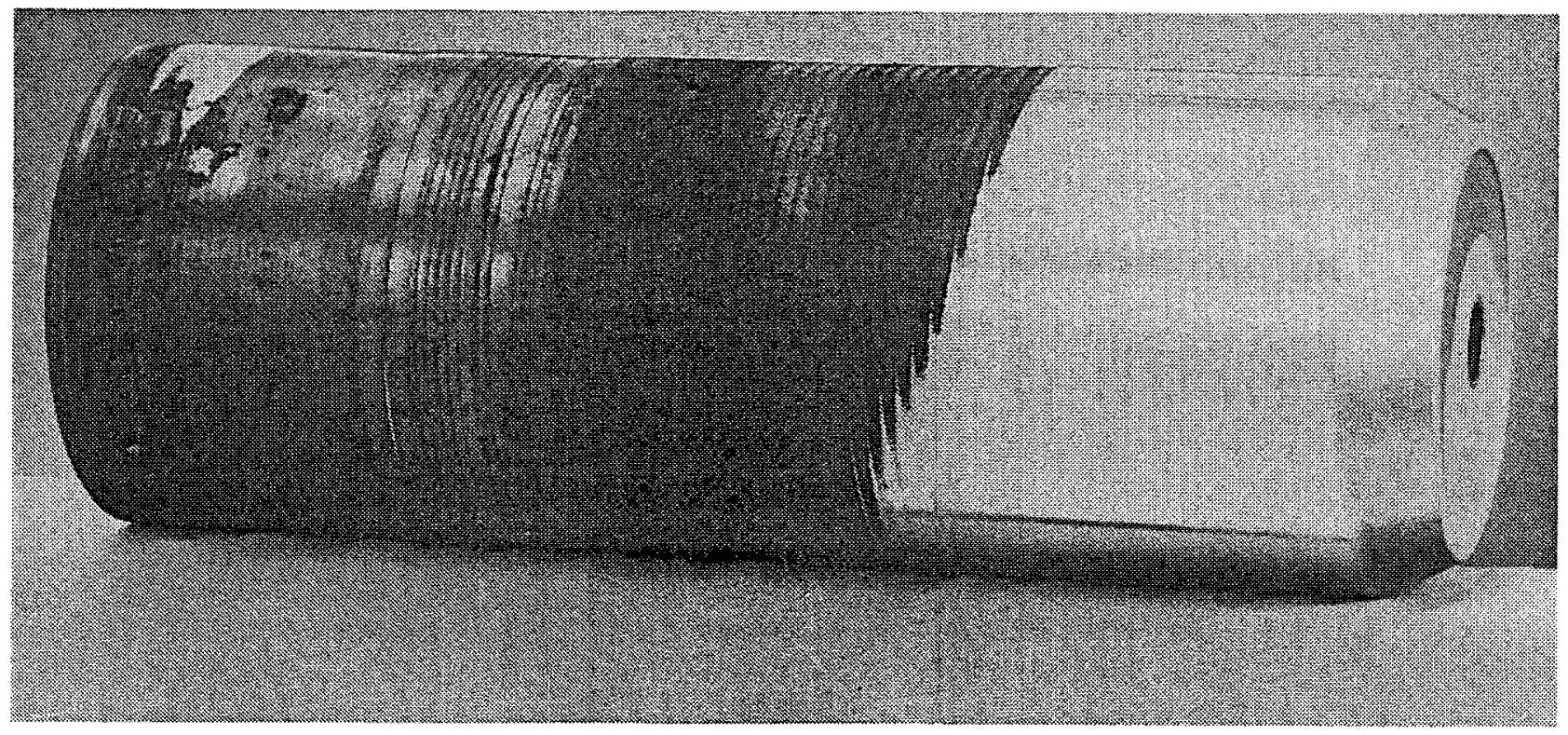

Figure 8. 250 Maraging Part Formed on Single Roller Forming Machine, Showing Hole Required in End of Part

some material and machining dollars. However, elimination of the rough machining cuts does not produce as significant a cost reduction as elimination of the need for purchasing the forgings. In all three cases, a sizeable cost savings was calculated, and most of this savings is the result of lower spin forming costs as compared to forging.

The calculated cost savings for these three parts indicate that spin forming will save Bendix $3.4 \mathrm{million}$ dollars. This cost comparison did not include the additional tooling savings that spin forming has over forging. Also a significant time savings will be achieved by eliminating long procurement lead-times for forgings, and a new capability will be provided for Bendix to produce development hardware from flat plate or rolled and welded preforms. Development hardware currently must be machined from solid bar or rolled and welded cylinders. A spin forming capability will reduce development material and machining costs and overall development time.

\section{ACCOMPLI SHMENTS}

Spin forming has been demonstrated as a feasible and economical fabrication technique for specific Bendix product applications. These applications include 250 maraging steel $6 \mathrm{Al}-4 \mathrm{~V}$ titanium alloy and 17-4 PH stainless steel. In each of these applications, spin forming is an economical alternate to long-lead-time procured forgings. 


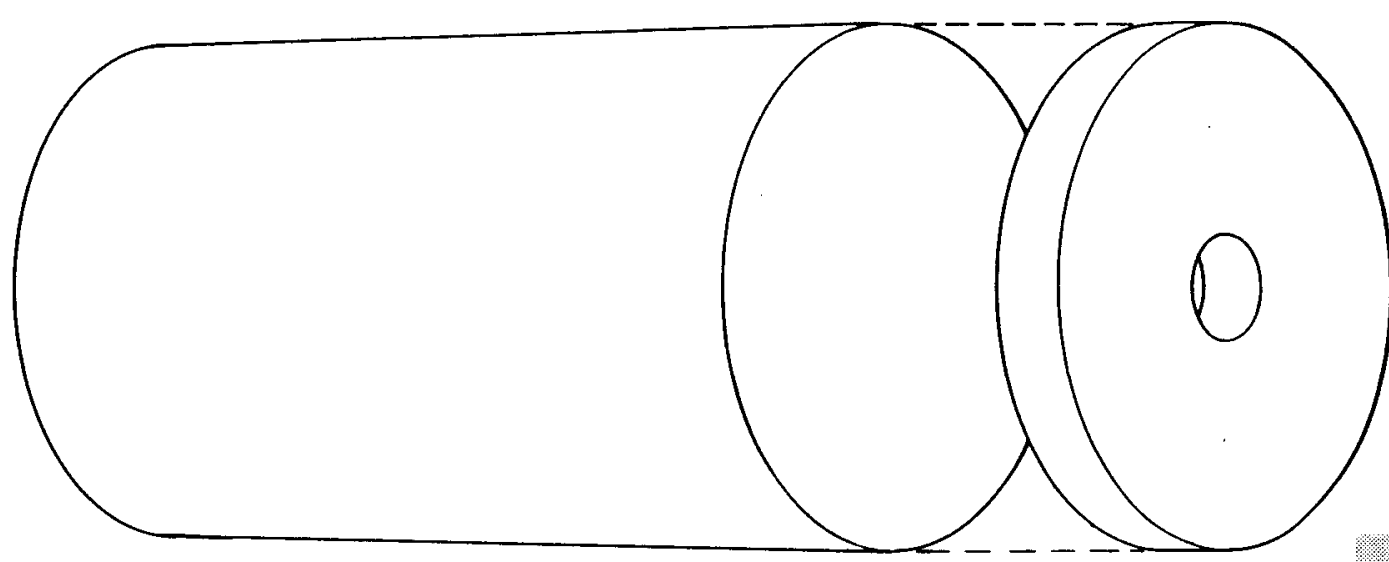

MACHINED

TITANIUM DISC

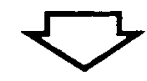

SPIN FORMED

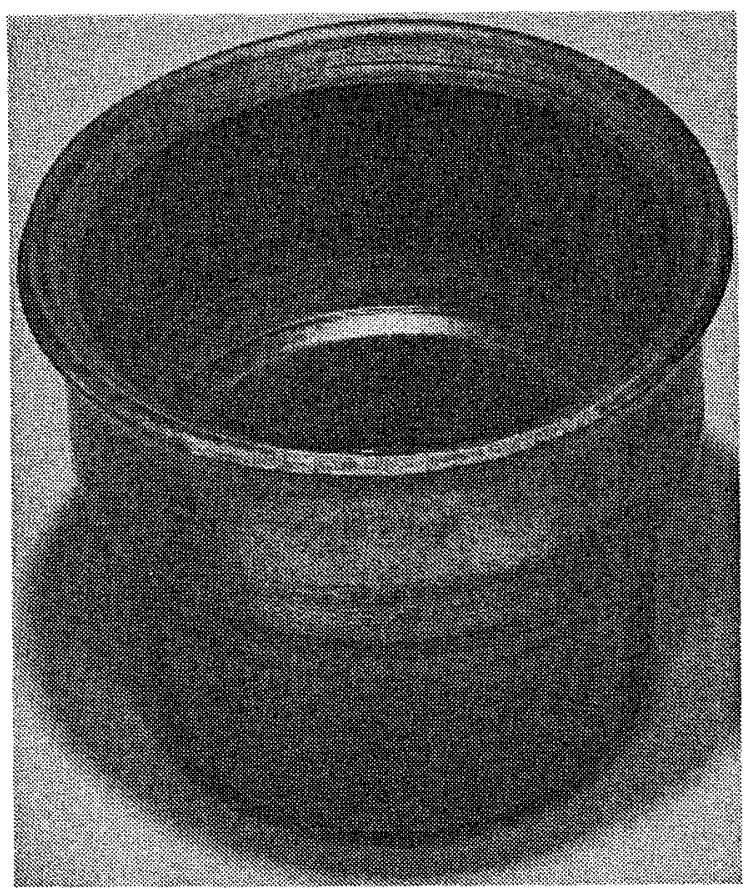

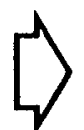

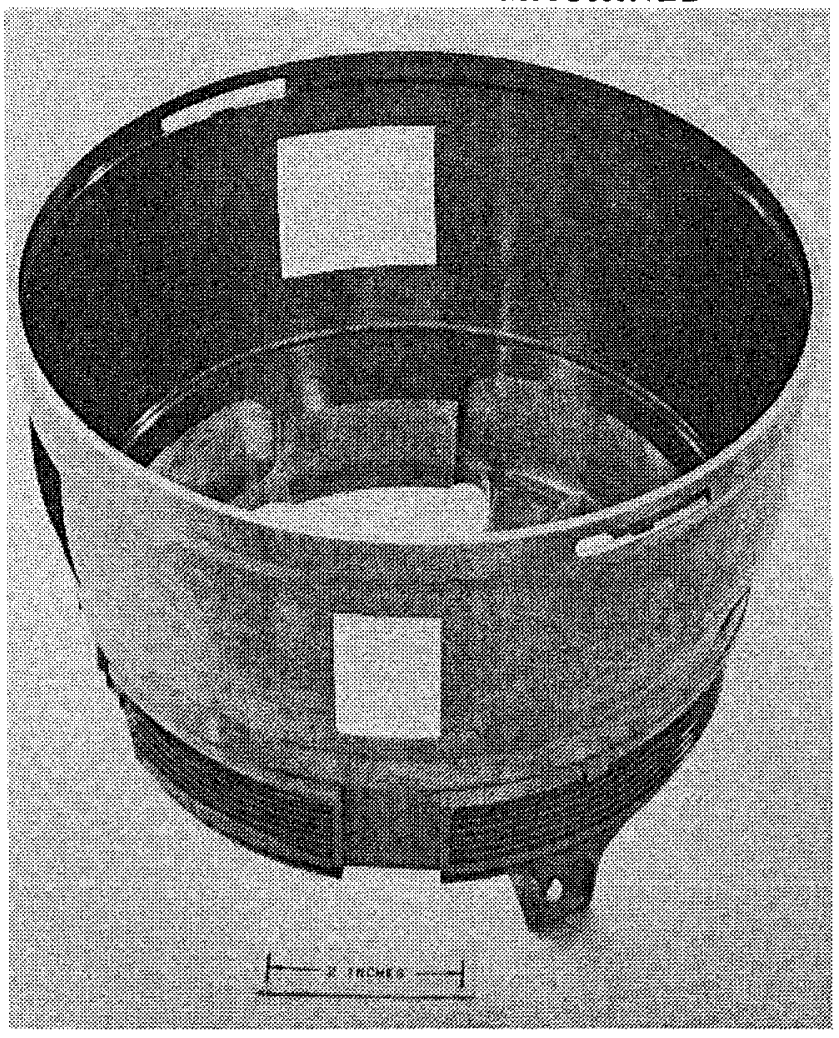

Figure 9. Major steps in spin Forming 6Al-4V Titanium Part 

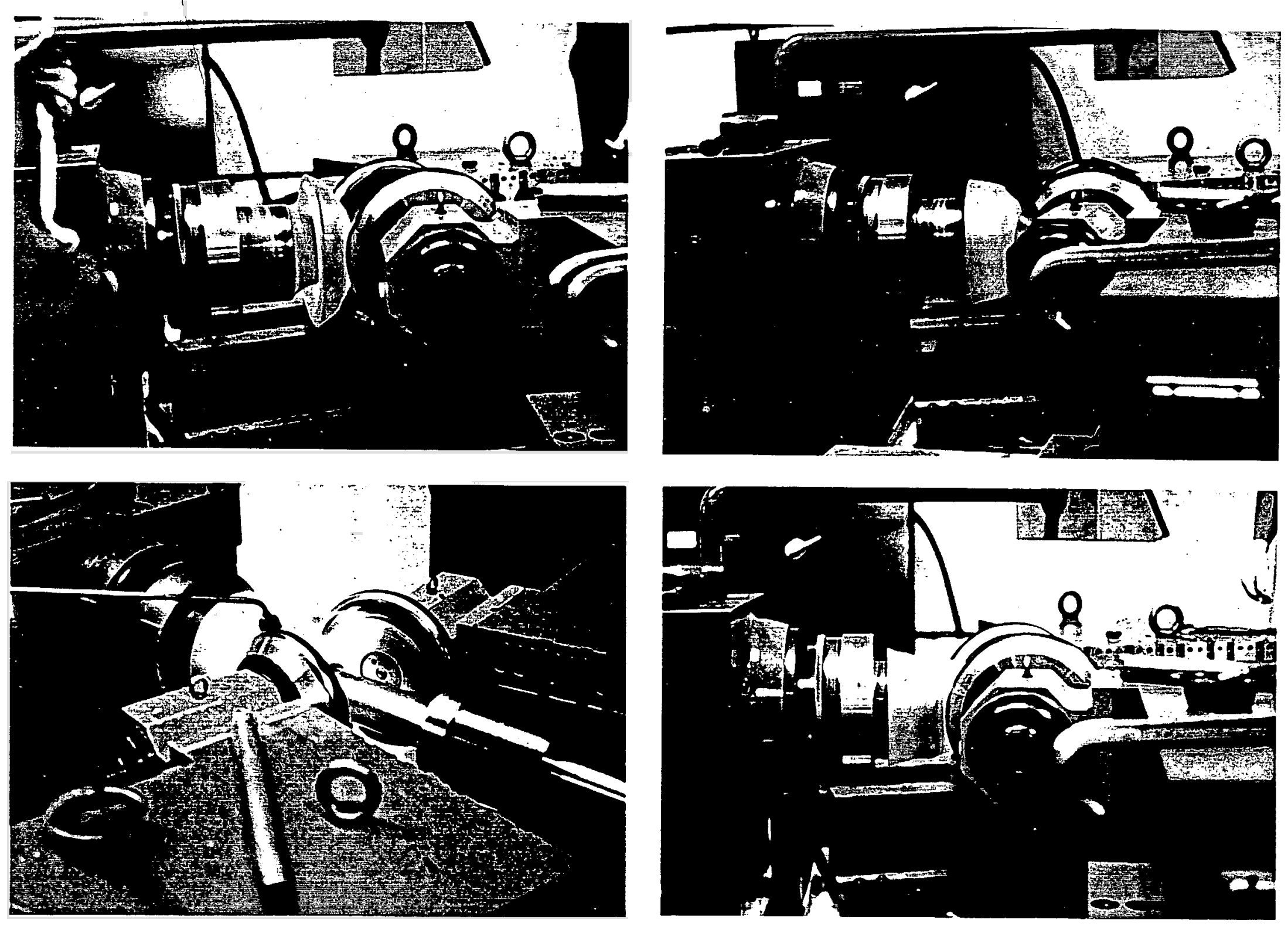

Figure 10. 6Al-4V Titanium Spin Forming Operations 

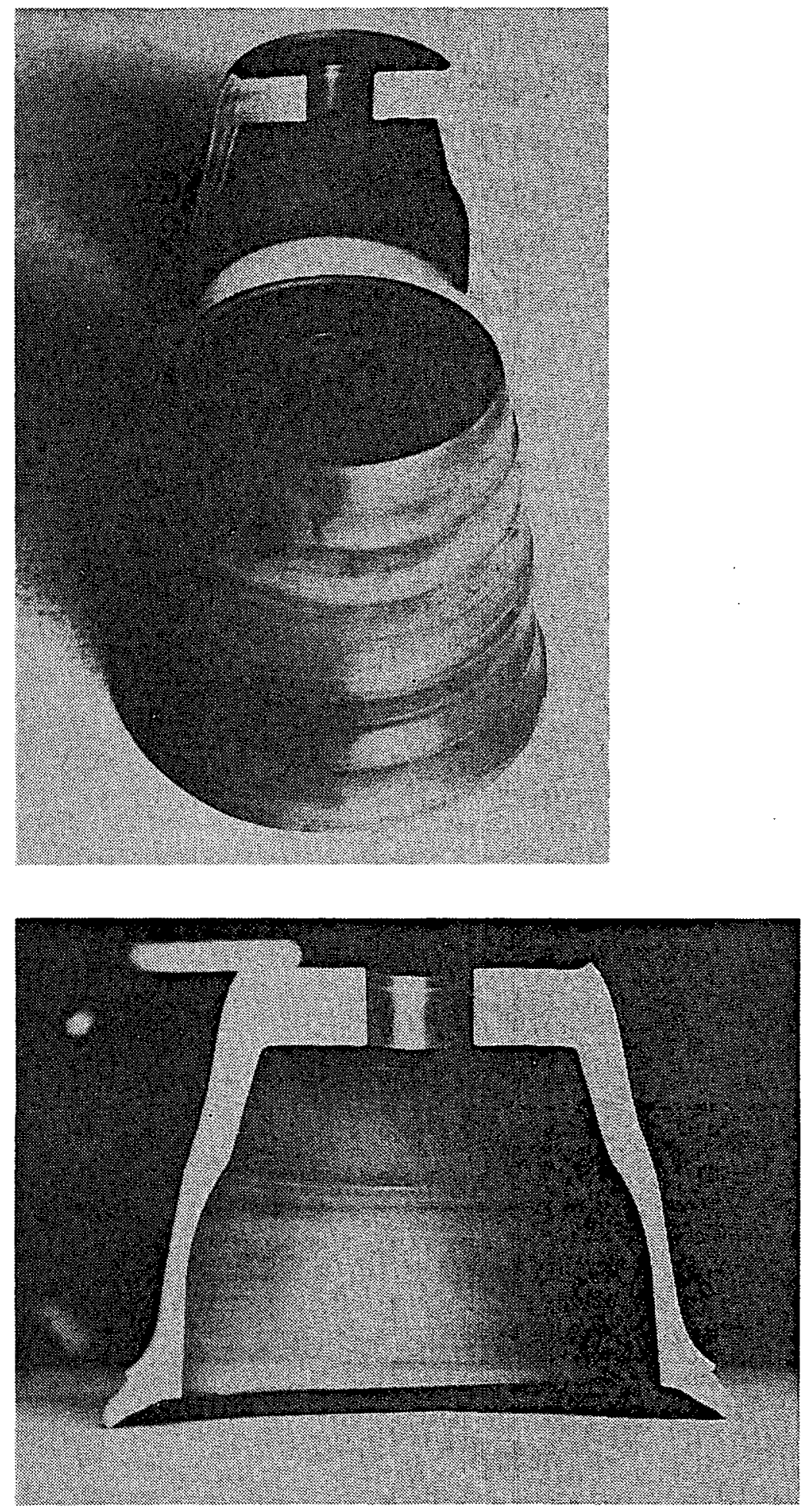

Figure 11. Hot Spin Formed Titanium Part, as Formed and Sectioned 


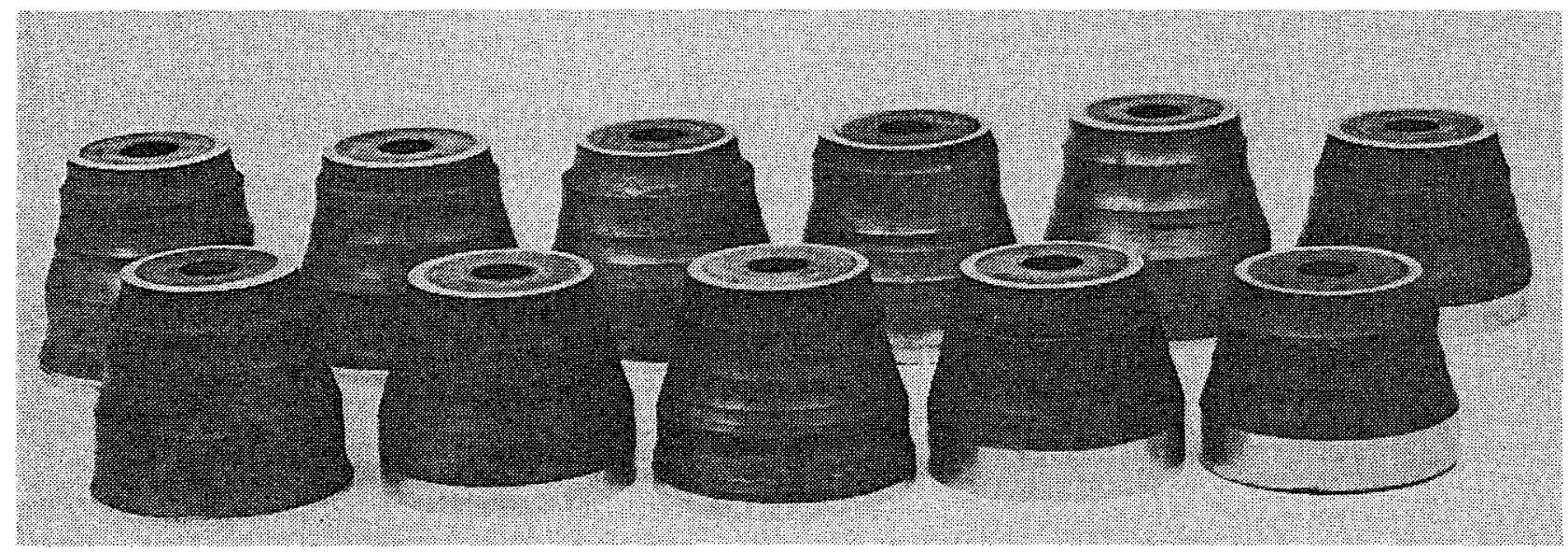

Figure 12. Hot Spin Formed 17-4 PH Stainless Steel Parts

\section{FUTURE WORK}

Continued work on this development project is required to document the economics, machined dimensional stability, and mechanical properties for these selected product applications. The 250 maraging steel evaluation is nearly complete, with six parts remaining to be machined and dimensionally evaluated. Twenty-five 6A1-4V titanium parts are being machined and compared to forgings to justify spin forming as an alternate production

: technique. Twelve Nitronic 40 parts are currently being press braked from plate into cylinders, welded, and spin formed. The dimensional stability and economics will be evaluated and compared to that of forging. Twenty-five 17-4 PH stainless steel test samples are being machined and evaluated as candidate substitutes for titanium forgings. Spin forming feasibility, economics, and resulting properties will be examined for other titanium parts.

Orders will be placed with existing equipment manufacturers to evaluate new equipment capabilities for spin forming applications. This evaluation will provide the information necessary to write the specifications required to purchase a spin forming machine. CAD/CAM support will be required to integrate the purchased spin forming equipment's computer into the Bendix system and to support computer design of spin forming mandrels and processes. Finally, after the spin forming equipment is installed at Bendix, evaluations will be required to define process parameters for other applications to provide the knowledge and experience necessary to support production at Bendix. 


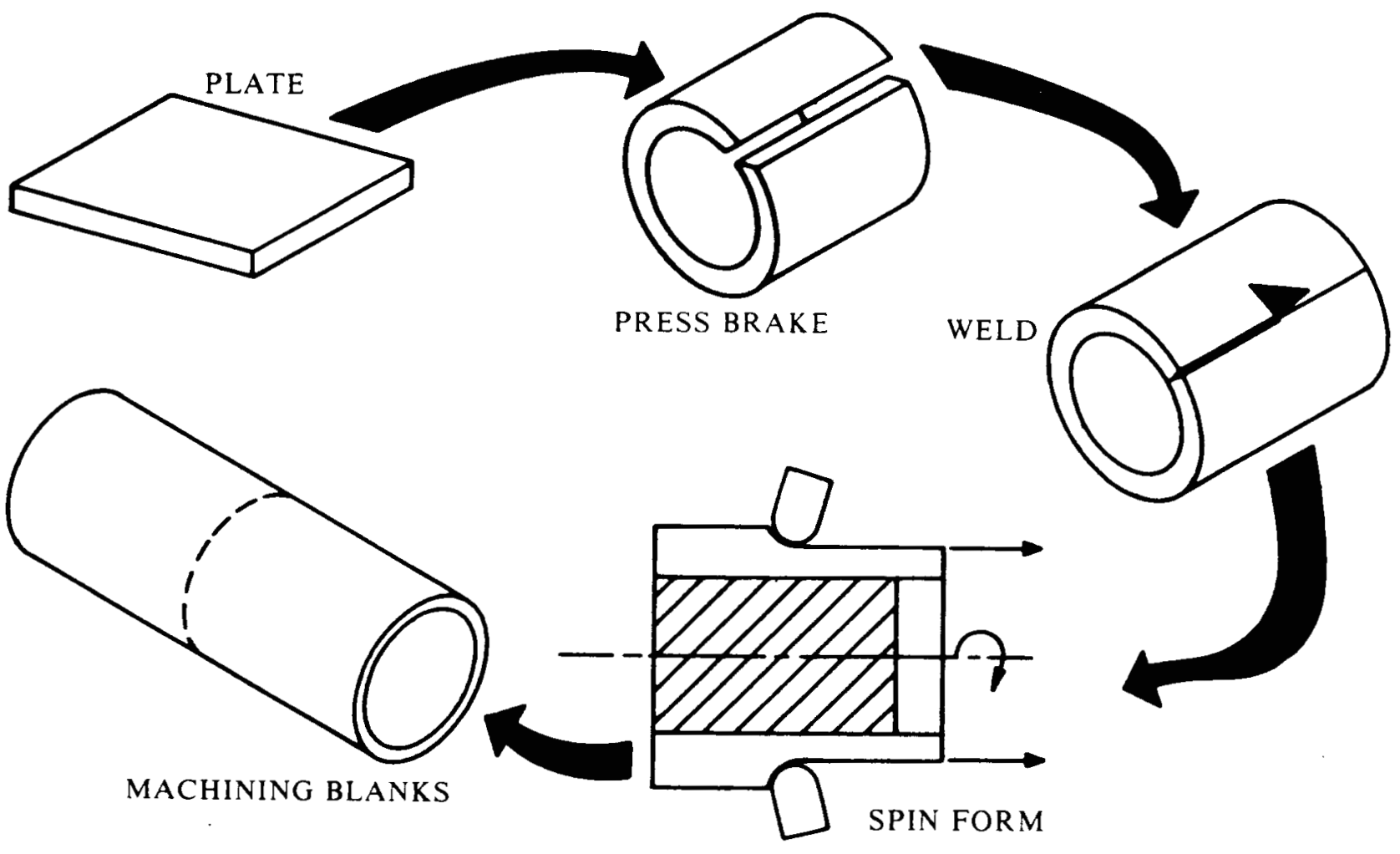

Figure 13. Major Steps in Producing Nitronic 40 Parts From Flat Plate 
$\mathrm{BDX}-613-2709$

SPIN FORMING DEVELOPMENT, W. G. Gates, Topical, Published May 1982.

Bendix product applications require the capability of fabricating heavy gage, high strength materials. Five commercial sources have been identified that have the capability of spin forming metal thicknesses greater than $9.5 \mathrm{~mm}$ and four equipment manufacturers produce machines with this capability. Twelve assemblies selected as candidates for spin forming applications require spin forming of titanium, 250 maraging steel, $17-4 \mathrm{PH}$ stainless steel, Nitronic 40 steel, 304 L stainless

MECHANICAL: Metal Forming

SPIN FORMING DEVELOPMENT, W. G. Gates, Topical, BDX-613-2709, Published May 1982.

Bendix product applications require the capability of fabricating heavy gage, high strength materials. Five commercial sources have been identified that have the capability of spin forming metal thicknesses greater than $9.5 \mathrm{~mm}$ and four equipment manufacturers produce machines with this capability. Twelve assemblies selected as candidates for spin forming applications require spin forming of titanium, 250 maraging steel, 17-4 $\mathrm{PH}$ stainless steel, Nitronic 40 steel, 304 L stainless

SPIN FORMING DEVELOPMENT, W. G. Gates, Topical, BDX-613-2709, Published May 1982.

Bendix product applications require the capability of fabricating heavy gage, high strength materials. Five commercial sources have been identified that have the capability of spin forming metal thicknesses greater than $9.5 \mathrm{~mm}$ and four equipment manufacturers produce machines with this capability. Twelve assemblies selected as candidates for spin forming applications require spin forming of titanium, 250 maraging steel, $17-4$ PH stainless steel, Nitronic 40 steel, 304 L stainless 
steel, and 6061 aluminum. Twelve parts have been cold spin formed from a 250 maraging. steel $8.1 \mathrm{~mm}$ wall thickness machine preform, and six have been hot spin formed directly from 31.8-mm-thick flat plate. Thirty-three $\mathrm{Ti}-6 \mathrm{Al}-4 \mathrm{~V}$ titanium alloy parts and $2617-4 \mathrm{PH}$ stainless steel parts have been hot spin formed directly from 31.8-mm-thick plate. Hot spin forming directly from plate has demonstrated the feasibility and favorable economics of this fabrication technique for Bendix applications.

steel, and 6061 aluminum. Twelve parts have been cold spin formed from a 250 maraging steel $8.1 \mathrm{~mm}$ wall thickness machine preform, and six have been hot spin formed directly from 31.8-mm-thick flat plate. Thirty-three. Ti-6AI-4V titanium alloy parts and $26 \quad 17-4 \mathrm{PH}$ stainless steel parts have been hot spin formed directly from 31.8-mm-thick plate. Hot spin forming directly from plate has demonstrated the feasibility and favorable economics of this fabrication technique for Bendix applications.

steel, and 6061 aluminum. Twelve parts have been cold spin formed from a 250 maraging steel $8.1 \mathrm{~mm}$ wall thickness machine preform, and six have been hot spin formed directly from $31.8-\mathrm{mm}-$ thick flat plate. Thirty-three $\mathrm{Ti}-6 \mathrm{Al}-4 \mathrm{~V}$ titanium alloy parts and $2617-4 \mathrm{PH}$ stainless steel parts have been hot spin formed directly from $31.8-\mathrm{mm}-$ thick plate. Hot spin forming directly from plate has demonstrated the feasibility and favorable economics of this fabrication technique for Bendix applications. 